\title{
Dynamic Rupture Simulations Based on the Characterized Source Model of the 2011 Tohoku Earthquake
}

\author{
Kenichi Tsuda, ${ }^{1}$ Satoshi Iwase, ${ }^{2}$ Hiroaki Uratani, ${ }^{3}$ Sachio Ogawa, ${ }^{1}$ Takahide Watanabe, ${ }^{1}$ Jun' ichi Miyakoshi, ${ }^{1}$ \\ and Jean Paul Ampuero ${ }^{4}$
}

\begin{abstract}
The 2011 Off the Pacific Coast of Tohoku earthquake (Tohoku earthquake, $M_{\mathrm{w}}$ 9.0) occurred on the Japan Trench and caused a devastating tsunami. Studies of this earthquake have revealed complex features of its rupture process. In particular, the shallow parts of the fault (near the trench) hosted large slip and long period seismic wave radiation, whereas the deep parts of the rupture (near the coast) hosted smaller slip and strong radiation of short period seismic waves. Understanding such depth-dependent feature of the rupture process of the Tohoku earthquake is necessary as it may occur during future mega-thrust earthquakes in this and other regions. In this study, we investigate the "characterized source model" of the Tohoku earthquake through dynamic rupture simulations. This source model divides the fault plane into several parts characterized by different size and frictional strength (main asperity, background area, etc.) and is widely used in Japan for the prediction of strong ground motion and tsunami through kinematic rupture simulations. Our characterized source model of the Tohoku earthquake comprises a large shallow asperity with moderate frictional strength, small deep asperities with high frictional strength, a background area with low frictional strength, and an area with dynamic weakening close to the trench (low dynamic friction coefficient as arising from, e.g., thermal pressurization). The results of our dynamic rupture simulation reproduce the main depth-dependent feature of the rupture process of the Tohoku earthquake. We also find that the width of the area close to the trench (equal to the distance from the trench to the shallow asperity, interpreted as the size of the accretionary prism) and the presence of dynamic weakening in this area have a significant influence on the final slip distribution. These results are useful to construct characterized source models for other subduction zones with different scale of the accretionary prism, such as the Chile subduction zone and the Nankai Trough. Dynamic rupture simulations based on the characterized source model might provide useful insights for hazard assessment associated with future megathrust earthquakes.
\end{abstract}

1 Ohsaki Research Institute, Inc., Chiyoda-ku, Tokyo, Japan. E-mail: kenichi.tsuda@shimz.co.jp

2 Chubu Electric Power Co., Inc., Nagoya-shi, Aichi, Japan.

3 Disaster Mitigation Research Center, Nagoya University, Nagoya-shi, Aichi, Japan.

4 Seismological Laboratory, California Institute of Technology, Pasadena, CA, USA.
Key words: The 2011 Off the Pacific Coast of Tohoku earthquake, characterized source model, dynamic rupture simulations, dynamic weakening, accretionary prism.

\section{Introduction}

Many studies of the 2011 Tohoku earthquake have shown that its rupture process was strikingly depth-dependent: the shallow parts of the fault, near the trench, produced large slip $(\sim 50 \mathrm{~m})$ and long period seismic waves (e.g., Suzuki et al. 2011) whereas the deep part of the rupture, near the coast, generated smaller slip and strong radiation of short period seismic waves (e.g., Kurahashi and Irikura 2013). Understanding such depth-dependent features of the Tohoku earthquake rupture process is important for the estimation of seismic and tsunami hazard caused by mega-thrust earthquakes even in other subduction zones. Indeed, other recent mega-thrust earthquakes, such as the 2010 Maule Chile earthquake $\left(M_{\mathrm{w}} 8.8\right)$ and the 2004 Sumatra earthquake $\left(M_{\mathrm{w}}\right.$ 9.2), showed similar depth-dependent rupture properties (e.g., Lay et al. 2012). Dynamic rupture modeling is an important tool to understand the mechanisms that generate these features (e.g., Huang et al. 2012, 2014; Hirono et al. 2016). For example, the 3D dynamic rupture model by Galvez et al. (2016) reproduced basic features observed in the seismic waveforms of the Tohoku earthquake.

Simplified source models are desirable to facilitate the construction of mega-thrust earthquake scenarios that can be used for hazard studies in many subduction zones. The "characterized source model" was introduced by Irikura and Miyake (2001) and is 
widely used in Japan as a kinematic source model for earthquake simulations to predict ground motions and tsunamis, because of its simplicity and easy applicability (e.g., Irikura and Miyake 2011). This model divides the fault plane into several characteristic parts (main asperity, background area, etc.) based on the heterogeneity of the slip and stress drop distributions. A characterized source model comprising strong motion generation areas (SMGA) and background area (e.g., Irikura et al. 2004) is used for strong ground motion prediction, especially to model short period seismic waves. One such model has been proposed for the Tohoku earthquake by Kurahashi and Irikura (2013). The characterized source model is also used for kinematic modeling of mega-thrust earthquakes, including large slip causing devastating tsunamis, by Japanese governmental organizations such as the Earthquake Research Committee (ERC) and the Cabinet Office. After the Tohoku earthquake, characterized source models for possible mega-thrust earthquakes in other Japanese regions, such as the Nankai Trough or Off-Boso (Southern Kanto earthquakes), were constructed to assist disaster prevention (e.g., Cabinet Office of Japan 2015). Thus, considering the characterized source model is very important.

In this study, we develop dynamic rupture models based on the characterized source model. Our goals are to examine the mechanisms of the complex rupture features of the Tohoku earthquake, and to investigate the applicability of dynamic simulation studies based on the characterized source model for the hazard estimation of future mega-thrust earthquakes. In Sect. 2.1, we construct a characterized source model of the Tohoku earthquake by integrating a large body of available information, including results from previous studies of the Tohoku earthquake (as reviewed in Tajima et al. 2013), historical seismicity along the Japan Trench (e.g., Koper et al. 2011) and subsurface velocity structure (e.g., Ito et al. 2005; Miura et al. 2005). In Sect. 2.2, we set the input parameters for dynamic rupture modeling on each area of the characterized source model. The results of our simulation, described in Sect. 3, reproduce the basic depth-dependent feature of the Tohoku earthquake. Our results provide useful insights on the development of future mega-thrust earthquake scenarios based on the characterized source model even for other subduction zones.

\section{Model}

\subsection{Characterized Model of the Tohoku Earthquake}

The Tohoku earthquake was a plate boundary mega-thrust earthquake which occurred on the Japan Trench, where the Pacific plate is subducting under the North American Plate. The rupture nucleated $100 \mathrm{~km}$ away from the trench axis and extended through a broad area of approximate dimensions of up to $500 \mathrm{~km}$ along strike and $200 \mathrm{~km}$ along dip (e.g., Suzuki et al. 2011). A vast amount of data has been obtained from this earthquake, including seismic, geodetic and tsunami data. We use inferences derived from that data to construct the characterized source model of the Tohoku earthquake sketched in Fig. 1. We also include the results from laboratory investigation of samples of fault materials that Kurahashi and Irikura (2013) did not consider.

Slip distribution models of the Tohoku earthquake have been inferred by many studies (as reviewed in Tajima et al. 2013). In most of them the area of largest slip is shallower than the hypocenter (e.g., Suzuki et al. 2011). Fujiwara et al. (2011) reported that the slip close to the trench reached around $50 \mathrm{~m}$ based on bathymetry differences before and after the earthquake. The stress drop distributions were estimated based on the slip distributions (e.g., Bletery et al. 2014; Brown et al. 2016).

While the locations of large slip, inferred from long-period and static observations, are located on the shallow part of the fault, the areas of strong shortperiod wave radiation are deeper. This depth-dependence of the frequency content of the source was recognized by back-projection analysis of $1 \mathrm{~Hz}$ teleseismic waves (e.g., Meng et al. 2011). From modeling of short period seismic waves, Kurahashi and Irikura (2013) identified five SMGAs, located deeper than the hypocenter.

The SMGAs are spatially related to the historical seismicity. Koper et al. (2011) summarized the location of large slip with weak short-period radiation, smaller slip with strong short-period radiation and source areas of historical seismicity since the last 

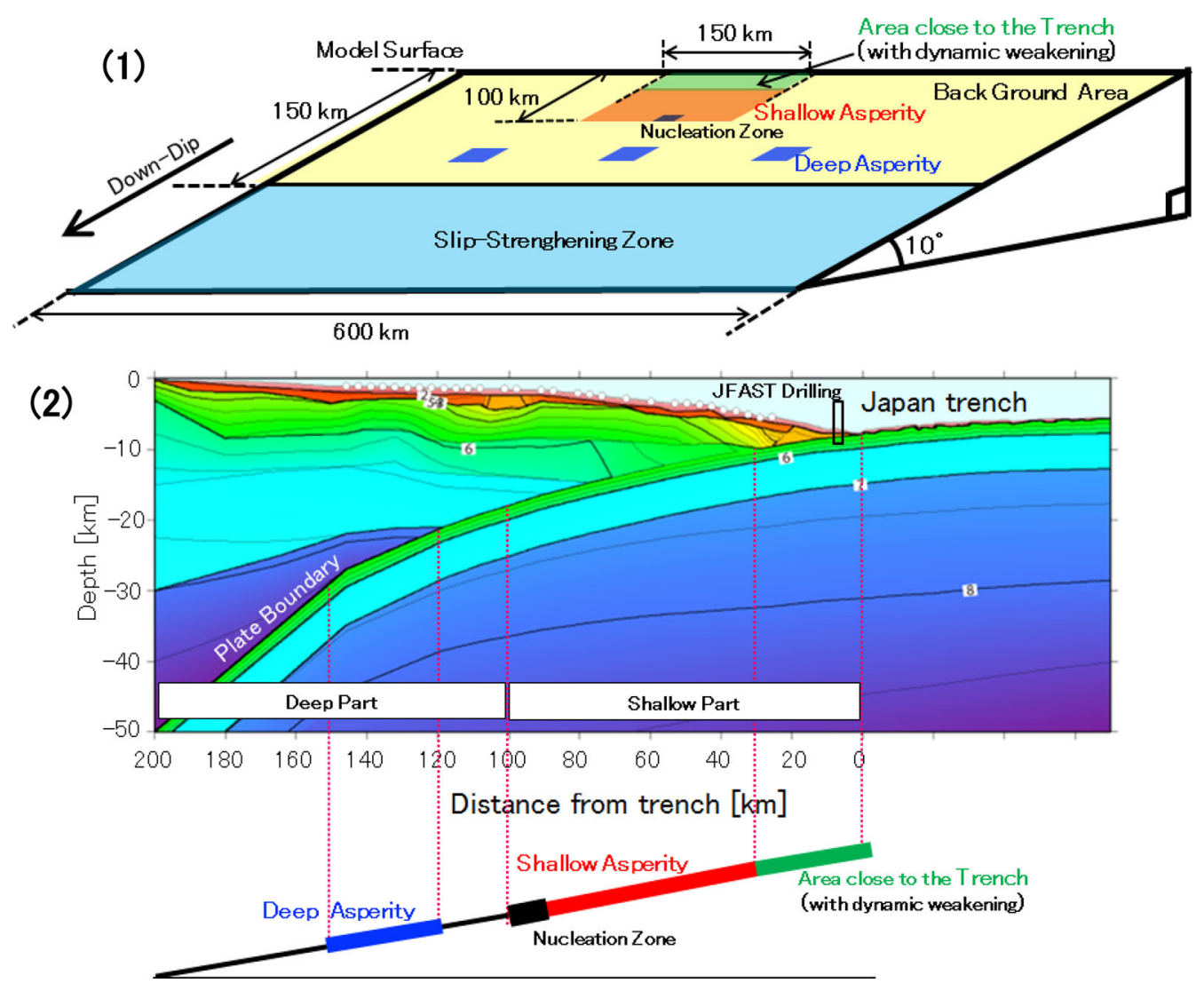

Figure 1

The characterized source model of the 2011 Tohoku earthquake; (1) model geometry, (2) comparison of a cross-section of the P-wave velocity structure (Miura et al. 2005; Cabinet Office of Japan 2011) around the Miyagi-Oki area and our model (box on the map represents the location of the JFAST drilling)

century. The source regions of earthquakes with moment magnitude $\left(M_{\mathrm{w}}\right)$ between 7 and 8 occurring every couple of decades in the Miyagi-Oki and Fukushima-Oki areas coincide with the deep areas of strong short-period radiation and smaller slip of the 2011 Tohoku earthquake. No large earthquakes occurred since the last century around the area of very large slip and long-period radiation of the Tohoku earthquake. Based on analysis of GPS data, Hashimoto et al. (2012) reported that the areas with large slip deficit during the seismically calm period 1996-2000 correlate well with the large slip area during the Tohoku earthquake. This indicates that strongly coupled asperities exist also on the shallow part of the fault.

However, the weak short-period radiation in the shallow part of the fault during the Tohoku earthquake and the occurrence of tsunami earthquakes, such as the 1896 Meiji-Sanriku tsunami earthquakes, indicate that the strongly-coupled shallow asperity is relatively weak (low frictional strength), large and has a relatively low stress drop. In the deeper part of the fault, the regular occurrence of earthquakes with $M_{\mathrm{w}} 7-8$ and the strong shortperiod radiation during the Tohoku earthquake suggest that the deep asperities are small (around $30 \mathrm{~km}$ along strike and $40 \mathrm{~km}$ along dip, Kurahashi and Irikura 2013), strong (high frictional strength) and have large strength drop (large fracture energy, Ide and Aochi 2013). In this view, while strain at depth was regularly released by the occurrence of earthquakes with $M_{\mathrm{w}} 7-8$ on the deep asperities, strain accumulated in the shallow, locked asperity and was released at once during the 2011 Tohoku earthquake. 
The area close to the trench was usually thought to generate little slip (small stress drop) during earthquake ruptures because frictionally stable shallow fault materials and very soft material in the hanging wall hamper stress accumulation (e.g., Wang 2013). This might raise the question of whether the shallow asperity that produced very large slip during the Tohoku earthquake extends to the trench or not. Obana et al. (2013) compared the locations of aftershock hypocenters of the 2011 Tohoku earthquake to the P-wave velocity distribution above $35 \mathrm{~km}$ depth around the Miyagi-Oki area (Ito et al. 2005), where the very large slip was produced during the Tohoku earthquake. The zone of the hanging wall from the trench to around $25 \mathrm{~km}$ from the trench has low P-wave velocity $(\leq 3.5 \mathrm{~km} / \mathrm{s})$ and hosts little seismicity after the Tohoku earthquake. In contrast, the area with relatively fast $\mathrm{P}$-wave velocity $(\geq 5.5 \mathrm{~km} / \mathrm{s}$ ) beyond $30 \mathrm{~km}$ from the trench has numerous aftershocks. The hanging wall zone close to the trench corresponds to the accretionary prism. Based on these observations, Hasegawa (2015) hypothesized that the area close to the trench where the megathrust underlies the accretionary prism has weak plate coupling. Furthermore, laboratory investigations of samples of fault materials collected from the area close to the trench on the Japan Trench by the JFAST drilling [e.g., Ujiie et al. 2013; Fulton et al. 2013; Fig. 1(2)] suggest the frictional strength of the plate boundary fault is very low and the fault zone materials are rich in clay (smectite). This composition promotes dynamic weakening by thermal pressurization during fault rupture around the area of the JFAST drilling [Fig. 1(2)].

Based on these observations, we consider in our model a shallow, strongly-coupled asperity located at $25 \mathrm{~km}$ from the trench and a shallower area between the trench and the shallow asperity with weak plate coupling and dynamic weakening. We refer to the latter as "area close to the trench" (Fig. 1). We also include smaller "deep asperities" with high frictional strength and large strength drop (Fig. 1).

\subsection{Simulation Conditions}

Based on the characterized source model of the Tohoku earthquake, we set the initial stresses and friction properties of each area shown in Fig. 1(1). As fault constitutive relation, we assumed the linear slipweakening friction law (e.g., Ida 1972; Fig. 2). Here, we define the stress drop $(\Delta \sigma)$ as the difference between the initial shear stress and the dynamic frictional stress, and the strength drop as the difference between the yield stress and the dynamic frictional stress (Fig. 2). This strength drop is related to the fracture energy. While little information about absolute initial stresses is available, the stress drop (e.g., Fig. 2) can be estimated by the analysis of seismic waves. The model parameter distributions are shown in Fig. 3.

The stress drop in the shallow asperity increases from 4 to $8 \mathrm{MPa}$ as a function of depth, inspired from the results of Bletery et al. (2014), whose inferred stress drop values are relatively low compared to other studies. The strength excess (SE, defined as the difference between yield stress and initial shear stress) is determined by the assumption that the stress ratio $(S=\mathrm{SE} / \Delta \sigma)$ equals 1 in the shallow asperity. The value of $S$ is known to affect rupture speed (e.g., Dunham 2007; Kaneko and Lapusta 2010). The sensitivity of our results to this model parameter requires further study because of its uncertainty, arising mainly from uncertainties on dynamic friction coefficient and fluid overpressure in the fault zone.

The deep asperities have been reported to have high strength drop (20-30 MPa: e.g., Kurahashi and Irikura 2013). However, there is no significant slip in the deep asperities. Hence their stress drop should be small, even if their strength drop is high. Thus we set

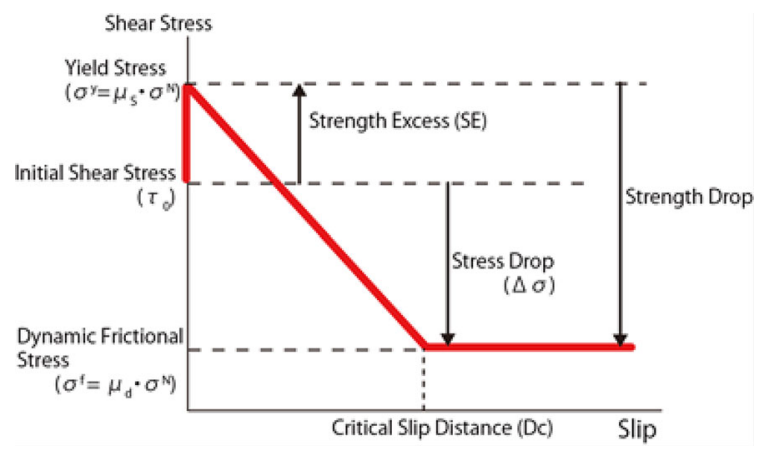

Figure 2

Slip-weakening friction law 

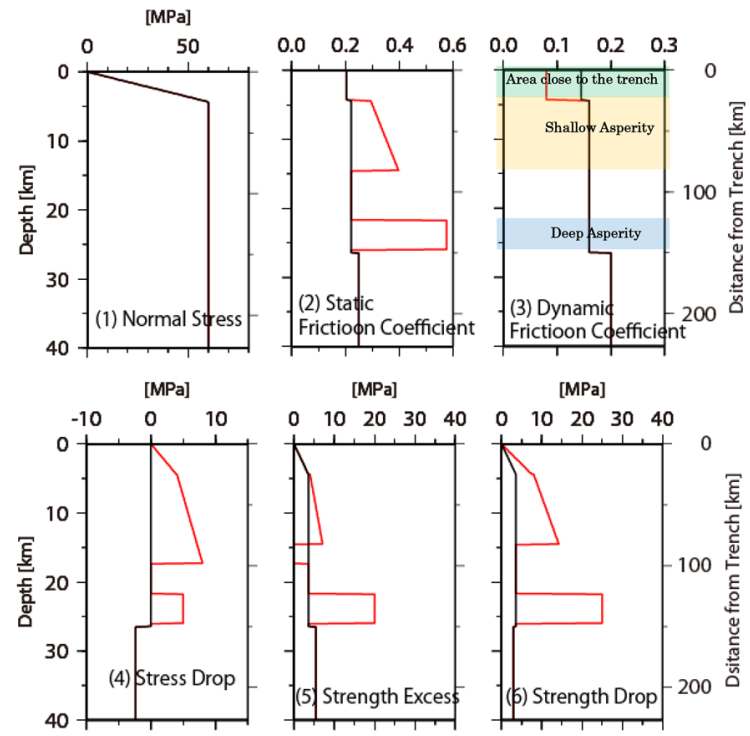

[MPa]

[MPa]
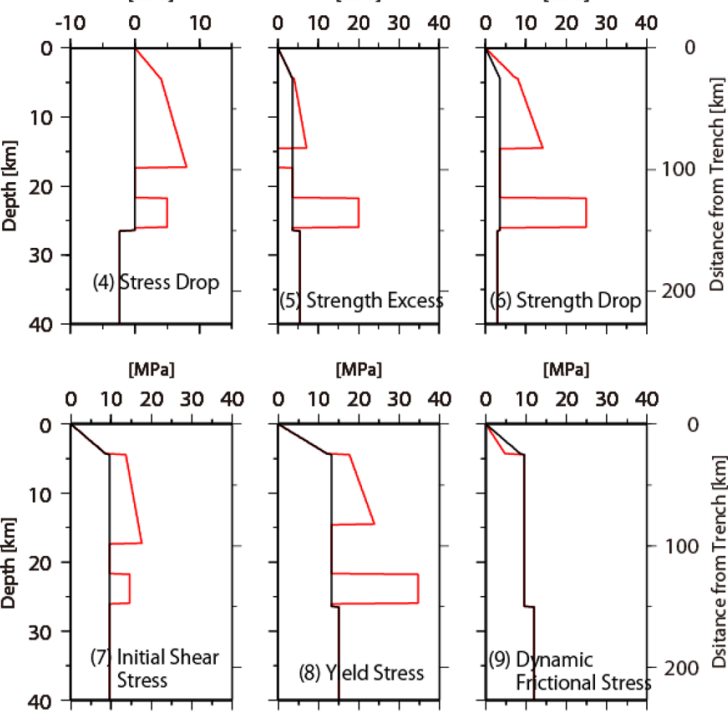

[MPa]

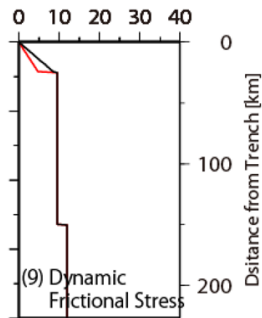

Figure 3

Initial parameter distributions as a function of depth. Red center of the model (including asperity). Black edge of the model

the strength drop to $25 \mathrm{MPa}$, the stress drop to $5 \mathrm{MPa}$, and the SE to $20 \mathrm{MPa}$, respectively.

Consistent with experimental studies on plate boundary fault materials (e.g., Ujiie et al. 2013), we set a low dynamic friction coefficient (0.08) in the area close to the trench [Fig. 1(2)] to represent fault weakening. In the background area we set zero stress drop and a strength excess of 3.6 MPa based on trialand-error in order to obtain a reasonable final rupture area (in our simulations the rupture stops spontaneously before it reaches the boundaries of the fault model). To arrest the rupture at depth, a slipstrengthening area with negative stress drop values is assumed beyond $150 \mathrm{~km}$ away from the trench. Comparison to the afterslip area of the Tohoku earthquake (e.g., Iinuma et al. 2012) suggests that our assumed seismogenic depth is reasonable.

The normal stress is assumed to be constant below the top edge of the shallow asperity. This assumption is motivated qualitatively by the overpressure model of Rice (1993), but the specific distribution of normal stress is chosen for simplicity given current uncertainties about the distribution of fluid pressure as a function of depth in the Tohoku mega-thrust. The distributions of initial shear stress and static friction coefficient are derived based on the slip-weakening relations (e.g., Fig. 2).

The slip weakening distance Dc affects ground motions but is difficult to constrain. Some have proposed to set Dc proportional to the size of asperities (Ide and Aochi 2013). Here we are mainly interested in the final slip distribution and assume a homogeneous $\mathrm{Dc}=1.6 \mathrm{~m}$. Finding reasonable Dc values to model the ground motions is left for future work.

We assume a planar fault surface and a homogenous medium $\left(V_{\mathrm{S}}=3.54 \mathrm{~km} / \mathrm{s}, \quad V_{\mathrm{P}}=6.3 \mathrm{~km} / \mathrm{s}\right.$, $\rho=2.7 \mathrm{~g} / \mathrm{cm}^{3}$ ) as a first step to gain a first-order understanding of the rupture process from basic dynamic modeling. We also set the nucleation zone at the bottom of the shallow asperity, roughly agreeing with the location of the hypocenter of the Tohoku earthquake [Fig. 1(2)]. Its size satisfies theoretical relations to promote spontaneous rupture (Galis et al. 2015). The simulation method used here is the 3D spectral element method (e.g., Galvez et al. 2014) and we used CUBIT to generate an unstructured mesh.

\section{Results}

Our characterized source model for the Tohoku earthquake successfully reproduces the main features of the slip distribution inferred by observational studies. The seismic moment for this simulation is approximately $5.4 \times 10^{22} \mathrm{Nm}\left(M_{\mathrm{w}} 9.1\right)$. The final slip distribution over the whole fault is shown in Fig. 4(1). The distributions of slip and peak slip-rate along dip on a section through the middle of the rupture [A-A' shown in the Fig. 4(1)] as a function of distance from trench is shown in Fig. 4(2). The rupture extends over an area of approximately $500 \mathrm{~km}$ along strike and $200 \mathrm{~km}$ along dip. The simulated slip in the shallow part of the fault is large $(\sim 50 \mathrm{~m})$ and the deep part of the rupture produced smaller slip $(\sim 20 \mathrm{~m})$, as observed for the Tohoku earthquake. The maximum slip is consistent with the values 

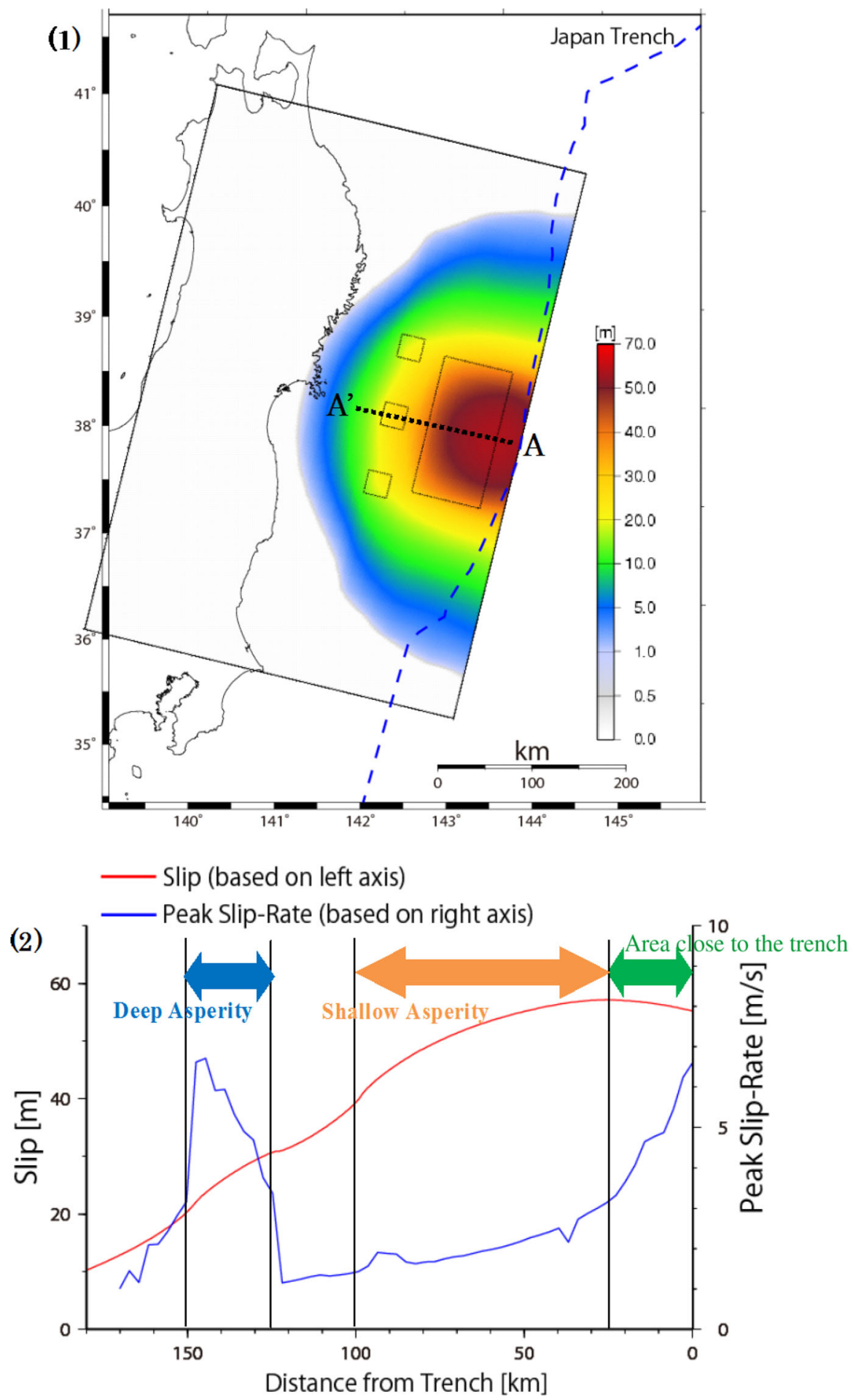

Figure 4

Simulation results for our characterized source model of the 2011 Tohoku earthquake: (1) final slip distribution of the model (dotted rectangles indicate the location of asperities), (2) distribution of slip (red, left axis) and peak-slip rate (blue, right axis) along the section of A$\mathrm{A}^{\prime}$ in (1) as a function of distance from trench 
estimated by source inversion analysis (e.g., Bletery et al. 2014; Sun et al. 2016) and by differential bathymetry (e.g., Fujiwara et al. 2011). The majority of the shallow slip results from the rupture of the shallow asperity.

To examine how the rupture propagates, we show the spatio-temporal distribution of slip-rate in Fig. 5. The shape of the slip-rate functions is qualitatively consistent with the depth-dependent seismic radiation of the Tohoku earthquake: in the shallow part (especially above shallow asperity) they are very smooth and in the deep part (around the deep asperities) they are very impulsive. The rupture propagates at a speed of about $3 \mathrm{~km} / \mathrm{s}$ inside the shallow asperity. It accelerates significantly at shallower depth due to the effect of reflected waves from the surface, which is especially strong when the fault dip is small (e.g., Huang et al. 2014). This rupture acceleration is accompanied by large slip-rate values close to the trench and is in contrast with most results of source inversion of the Tohoku earthquake showing slow rupture velocity close to the trench. We leave more detailed modeling consistent with inferred rupture speeds at shallow depth for future work.

Our characterized source model for the Tohoku earthquake successfully reproduces its depth-dependent radiation. In the deep part, the slip-rate functions are very impulsive and rich in short period features, corresponding to the radiation of short-period seismic waves by the deep asperities. The distributions of peak slip-rate and slip as a function of distance from the trench [Fig. 4(2)] show that the deep asperities produced large peak slip-rates but no significant slip. This trend is also recognized by comparing the Fourier amplitude spectra of slip rate at different depths (Fig. 6): in the deep asperity the amplitude at low frequencies $(\sim 0.01 \mathrm{~Hz})$ is the smallest, but above $0.3 \mathrm{~Hz}$ it becomes the largest. Close to the

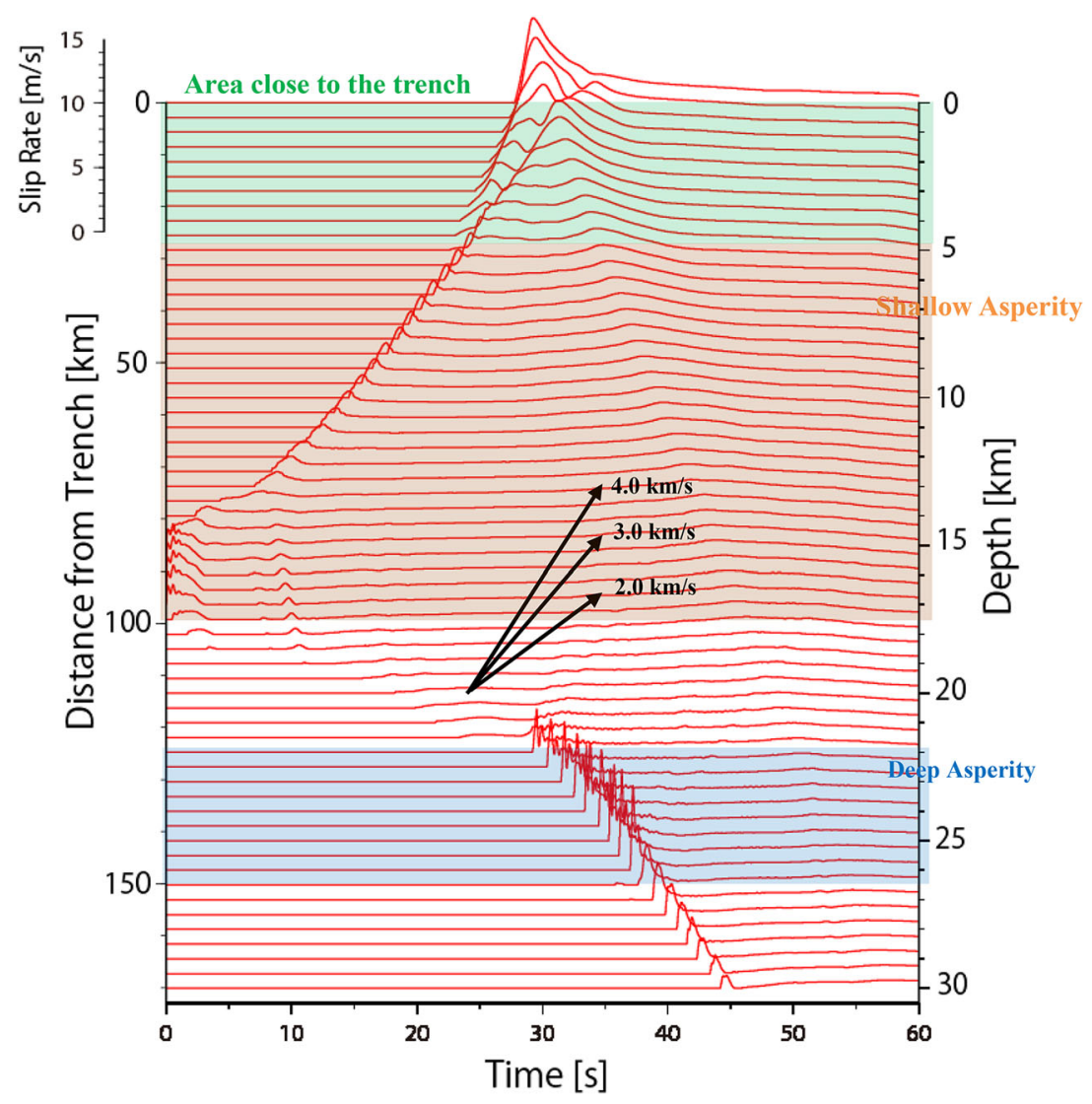

Figure 5

Slip-rate functions along a trench-normal profile through the center of the model 


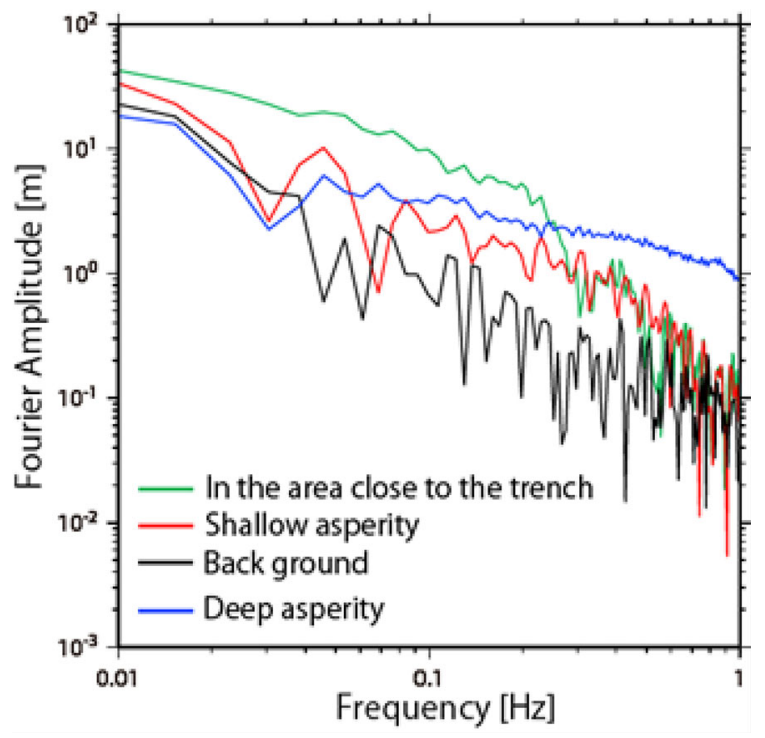

Figure 6

Fourier amplitude spectra of slip rate in different areas of the characterized source model

surface, the peak slip-rates are large but the highfrequency amplitudes are small, because the shallow area has little stress drop.
Additional simulations illustrate the role of stress and frictional strength of the deep asperities. To produce smaller slip and large short period seismic waves in the deep part of the rupture, we originally set a large strength drop (25 MPa, Fig. 2) but small stress drop (5 MPa, Fig. 2) in the deep asperities. We ran an additional simulation with stress drop changed to $20 \mathrm{MPa}$, while preserving the original strength drop (25 MPa). The resulting slip profiles are shown in Fig. 7. Slip around the deep asperity becomes very large $(>40 \mathrm{~m})$ and its spatial distribution becomes significantly peaked. Because this feature conflicts with the observed slip of the Tohoku earthquake, we consider that our original assumption of stress and frictional strength in deep asperities was reasonable.

\section{Discussion}

The dynamic rupture simulation results based on our characterized source model of the Tohoku earthquake agree with the main features of slip distribution observed in this event. Here we discuss what

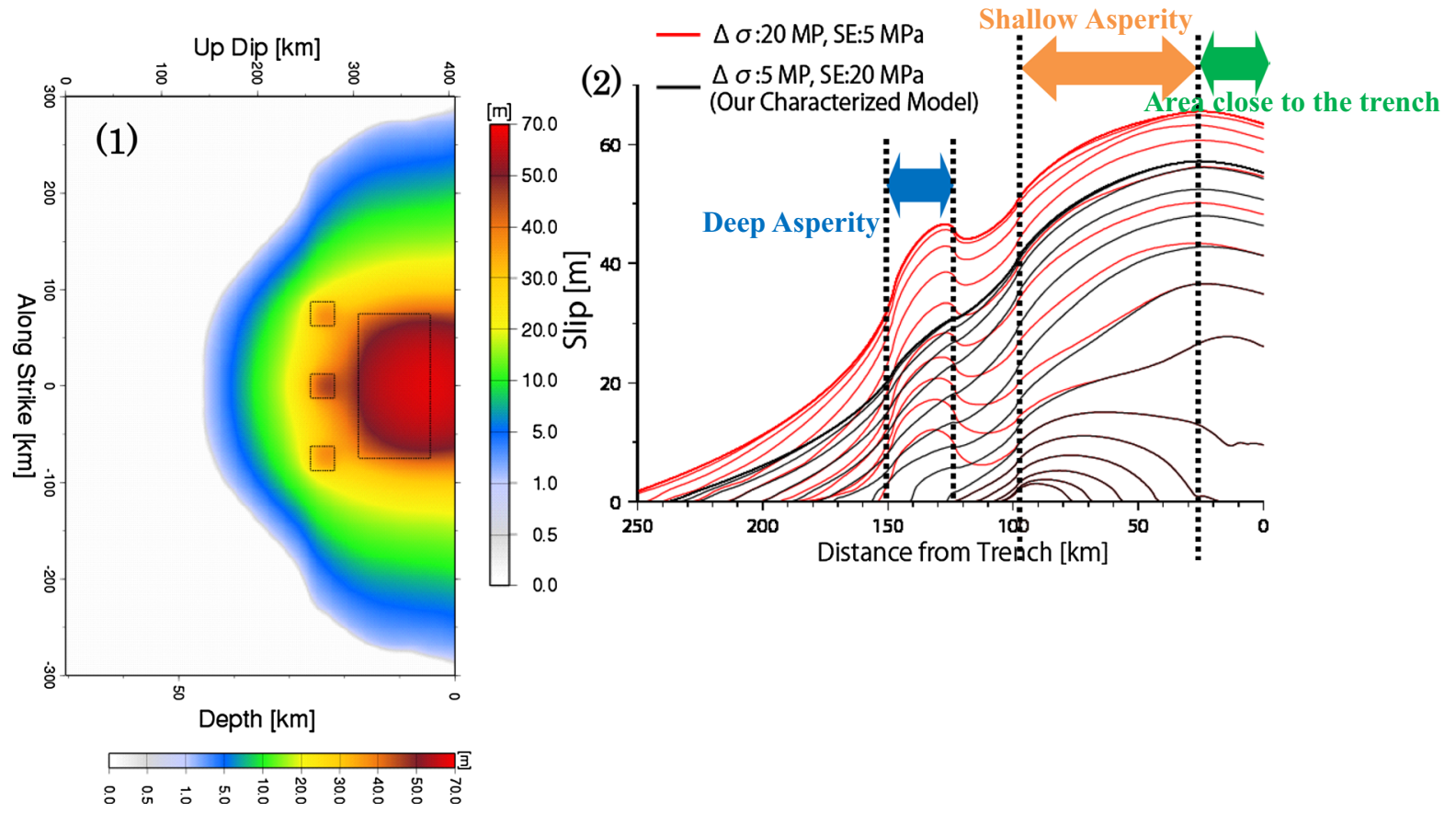

Figure 7

Effect of stress drop of deep asperities on slip. (1) Final slip distribution of a model with higher stress drop in the deep asperity but same strength drop (dotted rectangles indicate the location of asperities). (2) Slip distribution at the center of the model at every $5 \mathrm{~s}$ as a function of distance from trench. Slip of the reference model is also shown. $\Delta \sigma$ is the stress drop and SE is the strength excess (Fig. 2) 
aspects of the model are essential to achieve this agreement. Our characterized source model of the Tohoku earthquake comprises a large shallow asperity with moderate frictional strength, small deep asperities with high frictional strength, a background area with low frictional strength, and a near-trench area with dynamic weakening.

The areas of our model that control the large shallow slip are the shallow asperity and the area close to the trench. The role of the relative stress drop of these two areas on the final slip profile was also illustrated in 2D dynamic simulations by Huang et al. (2014) and can be understood from results of 2D static analysis by $\mathrm{Hu}$ and Wang (2008). Following Hasegawa (2015), we hypothesized that the location of the area close to the trench coincides with the accretionary prism. The properties of these areas can be different in other subduction zones and this difference might contribute to the global variability of mega-thrust earthquakes. For example, the size of the accretionary prism differs across subduction zones (e.g., Bilek 2010), it is smaller in the Tohoku trench than in the Nankai Trough (e.g., Tsuru et al. 2002; Nakanishi et al. 2003). Also Ujiie et al. (2013) and
Hirono et al. (2016) found differences of slip-weakening properties between the Tohoku trench and the Nankai Trough based on laboratory experiments using materials collected by deep hole drilling projects (e.g., JFAST for the Japan Trench and NanTroSEIZE for the Nankai Trough). Therefore, we investigate how the slip distribution changes when the width of the area close to the trench related to the accretionary prism (the distance from the trench to the shallow asperity) is larger and no dynamic weakening occurs. To focus on the effects on shallow slip, we start from a reference simulation removing the deep asperities from our characterized source model of the Tohoku earthquake.

First, because the accretionary prism around the Miyagi-Oki area, where the large slip was generated during the Tohoku earthquake, is particularly narrow (Tsuru et al. 2002), we considered an additional model with larger accretionary prism (longer area close to the trench), as can be found in other subduction zones. The resulting slip profile on a section through the middle of the rupture is shown as the blue line in Fig. 8 compared to the reference model (black). Dynamic weakening promotes slip but the

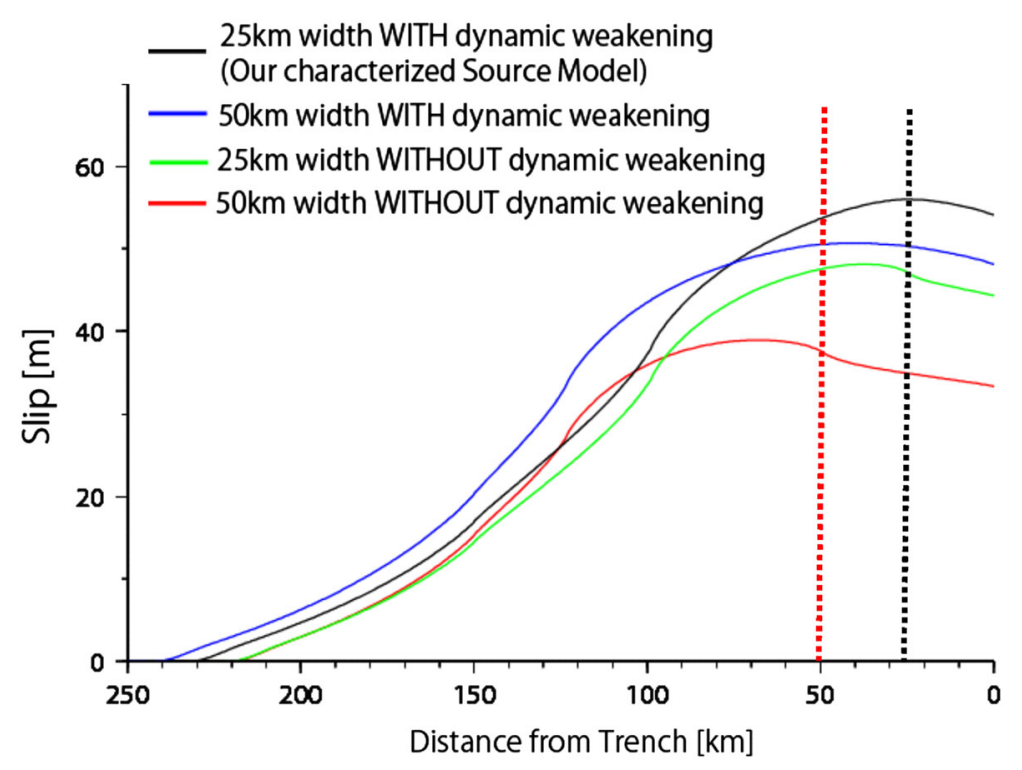

Figure 8

Comparisons of the slip distribution along the dip at the center of the model as a function of distance from trench. The vertical dotted lines correspond to the lines of the boundaries between the shallow asperity and the area close to the trench. The black line denotes $25 \mathrm{~km}$ width and the red line denotes $50 \mathrm{~km}$ width of the area close to the trench, respectively 
stress drop in the shallow dynamic weakening area is smaller than in the shallow asperity right beneath it, which leads to smaller slip (around 10\% smaller) close to the trench in the model with larger accretionary prism.

Next, we ran an additional simulation in which the reference model was modified by assuming no dynamic weakening in the area close to the trench. The resulting slip profile is shown in Fig. 8 (green line). After the rupture passes through the shallow asperity, the differences become larger. Because of the low stress drop at shallow depth in the model without shallow dynamic weakening, the slip close to the trench is smaller (by about 15\%) than when dynamic weakening is present.

Finally, we ran a simulation with long accretionary prism and without dynamic weakening. The resulting slip, shown as the red line in Fig. 8, is even smaller close to the trench (by almost 40\%). This might be an extreme scenario, but considering the sensitivity of slip to these aspects of the model can guide the development of characterized source models for subduction zones with different scales of accretionary prism, such as the Chile subduction zone and the Nankai Trough.

\section{Conclusion}

We have developed a dynamic rupture model based on a "characterized source model" of the 2011 Tohoku earthquake, constrained by the results of previous studies and observations. The model reproduces the basic depth-dependent features of slip distribution and short-period radiation of the Tohoku earthquake. Our simulation results indicate that the large slip observed on the shallow part of the fault arises from the combination of rupture of a shallow asperity with higher stress drop than its surroundings and dynamic weakening processes in the area close to the trench (low dynamic friction coefficient as arising from, e.g., thermal pressurization). We also find that the width of the near trench area related to the accretionary prism and the presence of dynamic weakening in this area have a significant influence on the final slip distribution.

Even though our characterized source model is a schematic, qualitative representation of the earthquake source properties, we have shown that dynamic rupture simulations based on this simplified model reproduce the basic features of the rupture process. The results of this study suggest that dynamic rupture modeling based on the characterized source model can provide useful insights for the hazard estimation associated with future mega-thrust earthquakes. The approach integrates results of GPS data analysis, subsurface structure investigations and experimental studies by deep-hole drilling projects such as JFAST. Further developments, such as incorporating non-planar fault geometry and heterogeneous medium, will be considered as next steps to validate the approach by quantitative comparison between predicted and recorded ground motions.

\section{Acknowledgements}

Discussions with Prof. Kelin Wang and David Oglesby helped improve the draft. We also appreciated very constructive comments by Dr. Luis Dalguer (guest editor) and two anonymous reviewers to elaborate the manuscript.

Open Access This article is distributed under the terms of the Creative Commons Attribution 4.0 International License (http:// creativecommons.org/licenses/by/4.0/), which permits unrestricted use, distribution, and reproduction in any medium, provided you give appropriate credit to the original author(s) and the source, provide a link to the Creative Commons license, and indicate if changes were made.

\section{REFERENCES}

Bilek, S. L. (2010). The role of subduction erosion on seismicity. Geology, 38, 479-480.

Bletery, Q., Sladen, A., Delouis, B., Vallée, M., Nocquet, J. M., Rolland, L., et al. (2014). A detailed source model for the Mw9.0 Tohoku-Oki earthquake reconciling geodesy, seismology and tsunami records. Journal Geophysical Research, 119, 7636-7653. doi:10.1002/2014JB011261.

Brown, L., Wang, K., \& Sun, T. (2016). Static stress drop in the $\mathrm{M}_{\mathrm{w}} 9$ Tohoku-oki earthquake: Heterogeneous distribution and low average value. Geophysical Research Letters, 42, 10595-10600. doi:10.1002/2015GL066361.

Cabinet Office of Japan (2011). Interim report of the source model study meeting of the giant earthquake along the Nankai Trough. http://www.bousai.go.jp/jishin/nankai/model/pdf/chukan_ matome.pdf. Accessed 20 July 2016 (in Japanese). 
Cabinet Office of Japan (2015). Report of the long-period ground motion study meeting of of the giant earthquake along the Nankai Trough. http://www.bousai.go.jp/jishin/nankai/ nankaitrough_report.html. Accessed 20 July 2016 (in Japanese).

Dunham, E. M. (2007). Conditions governing the occurrence of supershear ruptures under slip-weakening friction. Journal Geophysical Research, 112, B07302. doi:10.1029/ 2006JB004717.

Fujiwara, T., Kodaira, S., No, T., Kaiho, Y., Takahashi, N., \& Kaneda, Y. (2011). The 2011 Tohoku-Oki earthquake: Displacement reaching the trench axis. Science, 334, 1240. doi:10. 1126/science.1211554.

Fulton, P. M., Brodsky, E. E., Kano, Y., Mori, J., Chester, F., Ishikawa, T., et al. (2013). Low coseismic friction on the Tohoku-Oki fault determined from temperature measurements. Science, 342, 1214-1217. doi:10.1126/science.1243641.

Galis, M., Pelties, C., Kristek, J., Moczo, P., Ampuero, J. P., \& Mai, P. M. (2015). On the initiation of sustained slip-weakening ruptures by localized stresses. Geophysical Journal International, 200(2), 890-909.

Galvez, P., Ampuero, J. P., Dalguer, L. A., Somala, S. N., \& Nissen-Meyer, T. F. (2014). Dynamic earthquake rupture modelled with an unstructured 3-D spectral element method applied to the 2011 M9 Tohoku earthquake. Geophysical Journal International, 198(2), 1222-1240.

Galvez, P., Dalguer, L. A., Ampuero, J. P., \& Giardini, D. (2016). Slip reactivation during the $2011 \mathrm{Mw} 9.0$ Tohoku earthquake: Dynamic rupture and ground motion simulations. Bulletin of the Seismological Society of America, 106(3), 819-831. doi:10.1785/ 0120150153.

Hasegawa, A. (2015). What happened in the source area of the 2011 Tohoku-Oki earthquake?-the mechanism of the TohokuOki earthquake. Earthquake Journal, 60, 2-15. (in Japanese).

Hashimoto, C., Noda, A., \& Matsu'ura, M. (2012). The $M_{\mathrm{w}} 9.0$ northeast Japan earthquake: total rupture of a basement asperity. Geophysical Journal International, 189(1), 1-5. doi:10.1111/j. 1365-246X.2011.05368.x.

Hirono, T., Tsuda, K., Tanikawa, W., Ampuero, J. P., Shibazaki, B., Kinoshita, M., et al. (2016). Near-trench slip potential of megaquakes evaluated from fault properties and conditions. Scientific Reports, 6, 28184. doi:10.1038/srep28184.

Hu, Y., \& Wang, K. (2008). Coseismic strengthening of the shallow portion of the subduction fault and its effects on wedge taper. Journal Geophysical Research, 113, B12411. doi:10.1029/ 2008JB005724.

Huang, Y., Ampuero, J. P., \& Kanamori, H. (2014). Slip-weakening models of the 2011 Tohoku-Oki earthquake and constraints on stress drop and fracture energy. Pure and Applied Geophysics, 171(10), 2555-2568. doi:10.1007/s00024-013-0718-2.

Huang, Y., Meng, L., \& Ampuero, J. P. (2012). A dynamic model of the frequency-dependent rupture process of the 2011 TohokuOki earthquake. Earth, Planets and Space, 64(12), 1061-1066. doi:10.5047/eps.2012.05.011.

Ida, Y. (1972). Cohesive force across the tip of a longitudinal-shear crack and Griffith's specific surface energy. Journal Geophysical Research, 77, 3796-3805.

Ide, S., \& Aochi, H. (2013). Historical seismicity and dynamic rupture process of the 2011 Tohoku-Oki earthquake. Tectonophysics, 600, 1-13. doi:10.1016/j.tecto.2012.10.018.

Iinuma, T., Hino, R., Kido, M., Inazu, D., Osada, Y., Ito, Y., et al. (2012). Coseismic slip distribution of the 2011 off the Pacific
Coast of Tohoku Earthquake (M9.0) refined by means of seafloor geodetic data. Journal Geophysical Research, 117, B07409. doi:10.1029/2012JB009186.

Irikura, K., \& Miyake, H. (2001). Prediction of strong ground motions for scenario earthquake. Journal of Geography, 110, 849-875. (in Japanese with English abstract).

Irikura, K., \& Miyake, H. (2011). Recipe for predicting strong ground motion from crustal earthquake scenarios. Pure and Applied Geophysics, 168, 85-104. doi:10.1007/s00024-0100150-9.

Irikura, K, Miyake, H., Iwata, T., Kamae, K., Kawabe, H., Dalguer, L.A. (2004). Recipe for predicting strong ground motions from future large earthquakes. In 13th world conference of earthquake engineering, Vancouver, Canada.

Ito, A., Fujie, G., Miura, S., Kodaira, S., Kaneda, Y., \& Hino, R. (2005). Bending of the subducting oceanic plate and its implication for rupture propagation of large interplate earthquakes off Miyagi, Japan, in the Japan Trench subduction zone. Geophysical Reseach Letters, 32, L05310. doi:10.1029/2004GL022307.

Kaneko, Y., \& Lapusta, N. (2010). Supershear transition due to a free surface in 3-D simulations of spontaneous dynamic rupture on vertical strike-slip faults. Tectonophysics, 493, 272-284. doi:10.1016/j.tecto.2010.06.015.

Koper, K. D., Hutko, A. R., Lay, T., Ammon, C. J., \& Kanamori, H. (2011). Frequency dependent rupture process of the $2011 \mathrm{Mw}$ 9.0 Tohoku Earthquake: Comparison of short-period P wave back-projection images and broadband seismic rupture models. Earth, Planets and Space, 63, 599-602. doi:10.5047/eps.2011. 05.026.

Kurahashi, S., \& Irikura, K. (2013). Short-period source model of the 2011 Mw9.0 Off the Pacific Coast of Tohoku earthquake. Bulletin of the Seismological Society of America, 103(2B), 1373-1393.

Lay, T., Kanamori, H., Ammon, C. J., Koper, K. D., Hutko, A. R., Ye, L., et al. (2012). Depth-varying rupture properties of subduction zone megathrust faults. Journal Geophysical Research, 117, B04311. doi:10.1029/2011JB009133.

Meng, L., Inbal, A., \& Ampuero, J. P. (2011). A window into the complexity of the dynamic rupture of the $2011 \mathrm{Mw} 9$ TohokuOki earthquake. Geophysical Research Letters, 38, L00G07. doi:10.1029/2011GL04811.

Miura, S., Takahashi, N., Nakanishi, A., Tsuru, T., Kodaira, S., \& Kaneda, Y. (2005). Structural characteristics off Miyagi forearc region, the Japan Trench seismogenic zone, deduced from a wide-angle reflection and refraction study. Tectonophysics, 407, $165-188$.

Nakanishi, A., Kodaira, S., Park, J. O., \& Kaneda, Y. (2003). The relation between the source area of mega-thrust earthquake of the Nankai Trough and the distribution of back-strap. The Monthly Earth, 41, 126-134. (in Japanese).

Obana, K., Kodaira, S., Shinohara, M., Hino, R., Uehira, K., Shiobara, H., et al. (2013). Aftershocks near the updip end of the 2011 Tohoku-Oki earthquake. Earth and Planetary Science Letters, 382, 111-116. doi:10.1016/j.epsl.2013.09.007.

Rice, J. R. (1993). Spatio-temporal complexity of slip on a fault. Journal Geophysical Research, 93, 9885-9907.

Sun, T., Wang, K., Fujiwara, T., Kodaira, S., He, J. (2016). Large fault slip peaking at trench in the 2011 Tohoku-Oki earthquake. Nature Communications (accepted for publication).

Suzuki, W., Aoi, S., Sekiguchi, H., \& Kunugi, T. (2011). Rupture process of the 2011 Tohoku-Oki mega-thrust earthquake (M9.0) 
inverted from strong-motion data. Geophysical Research Letters, 38, L00G16. doi:10.1029/2011GL049136.

Tajima, F., Mori, J., \& Kennett, B. L. N. (2013). A review of the 2011 Tohoku-Oki earthquake (Mw 9.0): Large-scale rupture across heterogeneous plate coupling. Tectonophysics, 586, 15-34. doi:10.1016/j.tecto.2012.09.014.

Tsuru, T., Park, J.-O., Miura, S., Kodaira, S., Kido, Y., \& Hayashi, T. (2002). Along-arc structural variation of the plate boundary at the Japan Trench margin: Implication of interplate coupling.
Journal Geophysical Research, 107, 357. doi:10.1029/ 2001JB001664.

Ujiie, K., Tanaka, H., Saito, T., Tsutsumi, A., Mori, J., Kameda, J., et al. (2013). Low coseismic shear stress on the Tohoku-Oki megathrust determined from laboratory experiments. Science, 342, 1211-1214. doi:10.1126/science.1243485.

Wang, K. (2013). Megathrust surprises. Nature Geoscience, 6, 11-12. doi:10.1038/ngeo1682.

(Received July 31, 2016, revised November 10, 2016, accepted November 28, 2016, Published online January 11, 2017) 